\title{
Facing the 2013 Gold Rush: A Population Viability Analysis for the Endangered White-Lipped Peccary (Tayassu pecari) in Corcovado National Park, Costa Rica
}

\author{
Christian J. Rivera \\ Department of Ecology and Evolutionary Biology, Princeton University, Princeton, USA \\ Email: cjrivera@alumni.princeton.edu
}

Received 25 September 2014; revised 6 November 2014; accepted 23 November 2014

Copyright (C) 2014 by author and Scientific Research Publishing Inc. This work is licensed under the Creative Commons Attribution International License (CC BY). http://creativecommons.org/licenses/by/4.0/

(c) $\underset{\mathrm{EY}}{\mathrm{E}}$ Open Access

\begin{abstract}
The white-lipped peccary (Tayassu pecari) is facing range-wide declines throughout the Neotropics. It has been eliminated from about $89 \%$ of its historical range in Costa Rica. Corcovado National Park, in the Osa Peninsula of Costa Rica, is the last remaining stronghold for the white-lipped peccary in the country. In 2013, the Park experienced a sudden gold rush that brought with it a wave of 250 miners and vigorous hunting pressures on the population. Given that the species is endangered and is susceptible to hunting due to its herding behavior and tendency to cohere and attack when threatened rather than flee, it is important to assess its probability of extinction under various hunting scenarios. Incorporating data from studies on the life history of the species throughout its range in the Neotropics and in Corcovado, I used the population viability analysis software VORTEX to simulate the population trajectories and probabilities of extinction of the species under current hunting pressures and under various management scenarios. The results of this study revealed that under the 2013 scenario where 250 miners were present in the Park, the population of white-lipped peccaries has a about a $40 \%$ chance of extinction within five years and about a $99 \%$ chance of extinction within 10 years. Moreover, there is an "extinction threshold" for the population between the presence of 100 and 150 miners hunting in the Park. At this threshold, the population growth rate, $r$, drops from a positive growth rate $(r=0.09, \mathrm{SD}=0.08)$ to a negative one $(r=$ $-0.07, S D=0.29$ ). I suggest that anti-mining and anti-poaching laws be enforced immediately, and that the number of miners be reduced to 100 at a minimum, if not completely, in order to ensure that the population of white-lipped peccaries becomes viable and evades a local extinction.
\end{abstract}

\section{Keywords}

Corcovado National Park, Population Growth Rate, Population Viability Analysis, White-Lipped Peccary 


\section{Introduction}

\subsection{Corcovado National Park}

Home to a range of biological richness that has attracted scientists and tourists to the region for decades [1] Corcovado National Park (CNP) can be found in southwest Costa Rica in the Osa Peninsula. This region is part of the Mesoamerican biodiversity hotspot as defined by Myers et al. [2]. The protected area is about $470 \mathrm{~km}^{2}$ and is composed of a range of the following habitats: lowland rainforest, highland cloud forest, jolillo palm forest, mangrove swamps, marine coasts, and beach habitats. The Park receives around $5000 \mathrm{~mm}$ of rainfall annually, with the wettest months September and October and the driest months January to April [3] [4]. All six of Costa Rica's feline species as well as all four of its monkey species can be found in CNP. There are more than 6000 species of insects, 117 reptile and amphibian species, over 500 species of trees, more than 360 species of birds, and 140 species of mammals [1].

\subsection{The White-Lipped Peccary (Tayassu pecari)}

Amongst others, the Park is home to the endangered white-lipped peccary (Tayassu pecari), which has been eliminated from about $89 \%$ of its historical territory in Costa Rica and is now facing range-wide declines in Central and South America [5]. The conservation status of the white-lipped peccary in the IUCN Red List of Endangered Species has recently been changed from "near threatened" to "vulnerable" because of rapid population declines attributed to habitat loss, disease epidemics, competition with livestock, and illegal hunting [6].

Early studies by Kiltie [7] suggested that white-lipped peccaries serve as key ecosystem engineers by foraging around trees, roots, and shoots on the forest floor and significantly reducing the densities of certain fruits that grew near these objects. Foraging and herding behavior of the peccaries also results in wallows and puddles that collect water and serve as habitats for aquatic species [8]. Furthermore, they have been found to enhance the germination rates under parent palm trees and affect plant survival, recruitment, and spatial distribution; this is done by trampling, eating, and dispersing palm seeds [9]-[13].

In his early studies, Leopold [14] noted that white-lipped peccaries were amongst the first big mammals to become locally extinct when humans fragmented tropical forest habitats in Mexico and Central America. This is due to the synergistic effects of habitat loss and overhunting. Long-lived mammals such as the white-lipped peccary show greater declines in abundance than do short-lived mammals, thus making them more vulnerable to population declines and extirpation [15]. The lower productivity of white-lipped peccaries also makes the species more susceptible to hunting, compared to the collared peccary [16]. Herds form very strong cohesive units where individuals are rarely seen alone [17] [18]. Furthermore, individuals of this species prefer to confront threats and cohere when attacked, increasing their vulnerability to hunting when facing armed humans [19]-[21].

\subsection{Conflicts and Conservation}

Since its establishment, CNP has been the site of a conflict between conservation and the exploitation of its natural resources, notably logging, wildlife trading, poaching, and gold mining. Fortunately, ecotourism has helped create jobs so that locals can deviate from subsistence farming and hunting, logging, and mining. Despite these efforts, critical conservation issues still exist [22] [23].

In 2005, 30 - 40 illegal gold miners were reported to be active in CNP [23]. The numbers continued to increase and by 2013, 250 illegal gold miners had established themselves in CNP, building tunnels for mining gold and hunting the fauna of the Park for subsistence during the gold extraction operations. Law enforcement has not been able to impose severe restrictions on criminal activities, with those who are arrested for mining being released within a few days and facing minor penalties. The high levels of poverty in the region, due to failed reforestation projects and the departure of banana-producing companies, are accounting for the gold rush [24][26]. Moreover, the tunnels that are built disturb the landscape and vegetation of the Park and the extraction process, which involves mercury, contaminates the rivers and creeks [23].

On April 2013, the Ministry of the Environment sent an alert to the country in regards to the decline of jaguars (Panthera onca) in the Osa Peninsula [27]. Vice Minister of the Environment, Ana Lorena Guevera, declared that the decline of jaguars is attributed to the decline of the white-lipped peccary, which is the main food source for the jaguar and has been heavily hunted inside and outside the protected areas of the Peninsula as the 
number of gold miners has increased [27]. Furthermore, a 20-year study on the relative abundance of the white-lipped peccary and the jaguar has shown a declining trend [28]. Gold miners working illegally in CNP organize themselves in groups of 20 - 30 individuals and spend up to three weeks in the Park, hunting most animals they come across but relying on about two white-lipped peccaries per group to sustain them during that time [29] [CNP ranger, pers. comm.]. Other estimates of hunting inside CNP are lacking.

Before the 2013 gold rush, the areas that presented the most opportunistic hunting of white-lipped peccaries were the areas outside the Park borders [30] [31]. The conflict between the white-lipped peccaries and the people living in the surrounding towns and villages also exists because the animals eat the crops as they expand their foraging range during the end of the wet season in September [32]. Today, it is widely accepted that the only known threat driving the decline of the white-lipped peccary population is the intensive levels of poaching that occur within the Park, since the area is large enough to maintain a viable population of at least 500 individuals [27] [33] [34] [CNP ranger, pers. comm.] [E. Carrillo, pers. comm.] [J. C. Sáenz, pers. comm.].

In this study, my objective is to perform a population viability analysis (PVA) to model the population trajectories of white-lipped peccaries in CNP under various hunting pressure scenarios. PVAs are quantitative tools that use demographic and habitat data of a species to estimate probabilities of extinction or decline as well as chances of recovery given identifiable threats [35] [36]. I integrate published data on the life history of the species with known hunting levels as well as possible hunting scenarios. The scenarios include various numbers of illegal gold miners hunting in the Park. I will suggest the most appropriate conservation and management strategy to maintain a viable population of white-lipped peccaries in Corcovado National Park.

\section{Methods}

\subsection{Simulation of the Population}

I modeled the white-lipped peccary population using the population viability analysis software VORTEX (version 9.999). The software models deterministic forces and provides a "stochastic simulation of the extinction process" of wildlife populations. The iterations simulate the life cycles of sexually reproducing, diploid organisms based on life history parameters that are inputted by the user and various default values provided by VORTEX [37]. VORTEX models sequential events that describe an annual cycle of the species and individual organisms based on the inputted parameters and random probabilities. The results of the simulations provide a quantification of threats to extinction of the populations being modeled [36]. The efforts of Fuller et al. [38] have attempted to quantify the annual mortality rates of the white-lipped peccary population in CNP. The authors reported the survival and cause-specific mortality rates of adult male and female white-lipped peccaries over a period of six years. Using the mortality rates from this study, I ran a baseline simulation (Scenario 1) that excludes any mortality from poaching and thus models the population under no hunting pressure.

I set the initial population size for all simulations at 250 individuals. This was the average population size estimated to be present in the Park in 1999 [39] as well as in the beginning of 2013 [40]. I ran the simulations 1000 times for a period of 50 years in order to inform management strategies for the near future.

\subsection{Baseline Simulation of the White-Lipped Peccary Population (Scenario 1)}

A baseline scenario that models the trajectory of the white-lipped peccary population under no hunting pressure is needed to compare and assess population viability at various hunting levels. Table 1 lists the variables and values I obtained from the published literature to create the baseline simulation of the white-lipped peccary population. The following variables were obtained from studies performed directly on the white-lipped peccary population in Corcovado National Park: number of populations, reproductive system, female mortality, male mortality, initial population size, and carrying capacity. The baseline simulation (Scenario 1) models the population with mortality rates taken from Fuller et al. [38], which presents survival and death rates of the whitelipped peccaries in Corcovado. The mortality rates are calculated as the sum of the mortalities from the following causes of death: poaching, predation, accident, and unknown. For the purpose of this scenario, I did not take into account poaching mortality.

Because life history data on this species is limited, estimates had to be made for the following variables: percent of males in breeding pool, age distribution of initial population, and SD in carrying capacity (see Table 1). In their studies on the reproduction of white-lipped peccaries in CNP, Altrichter et al. [41] concluded that the 
Table 1. Life history and other parameters of the VORTEX model used to simulate the baseline scenario of the white-lipped peccary population in Corcovado National Park.

\begin{tabular}{|c|c|c|c|}
\hline Variable $^{\mathrm{a}}$ & Explanation/Notes & Value chosen & Reference \\
\hline \multicolumn{4}{|l|}{ Scenario Settings } \\
\hline \# of iterations & \# of times simulation is run & 1000 & \\
\hline \# of years & \# of years the population is modeled & 50 & \\
\hline Extinction definition & How extinction is defined in the model & 1 sex remains & \\
\hline \# of populations & \# of populations to be modeled & 1 & [40] \\
\hline \multicolumn{4}{|l|}{ Species Description } \\
\hline Inbreeding depression & The level and effect of inbreeding depression & $\begin{array}{l}3.14 \text { lethal equivalents; } \\
50 \% \text { due to alleles }\end{array}$ & [45] \\
\hline \multicolumn{4}{|l|}{ Reproductive System } \\
\hline Reproductive system & The mating system & Polygynous & {$[41]$} \\
\hline Age of first reproduction in F & Age at which $\mathrm{F}$ begin breeding & 2 & {$[44]$} \\
\hline Age of first reproduction in $\mathrm{M}$ & Age at which $\mathrm{M}$ begin breeding & 2 & [44] \\
\hline Maximum age of reproduction & Age of $\mathrm{F} / \mathrm{M}$ when breeding ends & 13 & [44] \\
\hline $\begin{array}{l}\text { Maximum \# of progeny } \\
\text { produced/year }\end{array}$ & Maximum \# of offspring produced/F/year & 3 & [16] \\
\hline Sex ratio at birth & Sex ratio of offspring at birth & $1: 1$ & [16] [41] \\
\hline $\begin{array}{l}\text { Density dependence in } \\
\text { reproduction }\end{array}$ & $\begin{array}{l}\text { Relationship between reproduction and } \\
\text { population density }\end{array}$ & No relationship assumed & \\
\hline \multicolumn{4}{|l|}{ Reproductive Rates } \\
\hline$\%$ of adult $\mathrm{F}$ breeding & Proportion of F breeding each year & $62 \%$ & {$[42]$} \\
\hline EV in \% breeding & $\begin{array}{l}\text { Environmental variation in \% of } \\
\text { adult } \mathrm{F} \text { breeding each year }\end{array}$ & 3.74 & [16] \\
\hline $\begin{array}{l}\text { Distribution of \# of } \\
\text { offspring/F/year }\end{array}$ & $\begin{array}{l}\text { Statistical distribution characterizing } \\
\text { the \# of offspring produced each year }\end{array}$ & Normal Distribution & \\
\hline Mean \# of offspring/F & & 2 & [16] \\
\hline SD in \# of offspring/F & & 0.5 & \\
\hline \multicolumn{4}{|l|}{ Mortality Rates } \\
\hline F mortality & Mortality of F as \% and SD & $18 \%, \mathrm{SD}=5.09$ & [38] \\
\hline M mortality & Mortality of $\mathrm{M}$ as $\%$ and SD & $3 \%, \mathrm{SD}=2.60$ & [38] \\
\hline Mortality for age categories & & $\begin{array}{l}\text { No variation in } \\
\text { survival across ages }\end{array}$ & [43] \\
\hline \multicolumn{4}{|l|}{ Mate Monopolization } \\
\hline$\%$ males in breeding pool & $\%$ of adult $\mathrm{M}$ breeding each year & $77 \%$ & \\
\hline \multicolumn{4}{|l|}{ Initial Population Size } \\
\hline $\begin{array}{l}\text { Age distribution of initial } \\
\text { population }\end{array}$ & $\begin{array}{l}\text { Distribution of individuals by age } \\
\text { at the beginning of the simulation }\end{array}$ & Stable age distribution & \\
\hline Initial population size & $\begin{array}{l}\text { Number of individuals at the } \\
\text { beginning of the simulation }\end{array}$ & 250 & $\begin{array}{c}\text { [39] [40] [J. C. } \\
\text { Sáenz, pers. comm.] }\end{array}$ \\
\hline \multicolumn{4}{|l|}{ Carrying Capacity } \\
\hline Carrying capacity (K) & Carrying capacity of the environment & 1000 & [3] \\
\hline $\mathrm{SD}$ in $\mathrm{K}$ & SD in carrying capacity of the environment & 200 & \\
\hline
\end{tabular}

${ }^{\mathrm{a}} \#=$ number, $\mathrm{F}$ = female, $\mathrm{M}=$ male, $\mathrm{EV}$ = environmental variability, $\mathrm{SD}$ = standard deviation. 
mating system of the species is a polygynous one. In such mating systems, a higher percentage of males than females breed in the population as a result of strong male-male competition over females. Bodmer [42] found that the proportion of females breeding per year in this species was 62\%. Because no life history data on the percent of male white-lipped peccaries that breed each year exists, and because it is known that the peccaries in CNP are dominated by a polygynous system, I assumed that about $15 \%$ more males than females are in the breeding pool.

There are also no data on the mortality rates for age categories of white-lipped peccaries, thus the variable mortality for age categories was taken from a study on an intensively hunted wild boar population (Sus scrofa) and assumes that there is no variation in survival across ages in the population [43]. The authors suggested that their results on the mortality rates of wild boar are comparable to rates of typical ungulates.

If the habitat carrying capacity changes over time due to variation in the environment (as is the case for the dry and wet season in CNP), it is suggested that a standard deviation for carrying capacity ( $K$ ) be included in VORTEX, and that this standard deviation be less than $K / 3$ in order to reduce the chance that $K$ drops to zero during the simulation [36]. Altrichter and Almeida [30] observed that the white-lipped peccaries might move beyond the boundaries of CNP to other forested regions of the Osa Peninsula (central and southeastern) at the end of the wet season (September-December). This suggests that seasonal changes may drive the size of the population because they can expand their range, thus it is important to account for a fluctuation in $K$. Because standard deviation in carrying capacity is entered as a number of animals in VORTEX, I assumed an estimated standard deviation of 200 individuals for a carrying capacity of 1000 individuals [3], which is less than K/3 (K/3 $\approx 333)$.

\subsection{Simulation of Known Hunting Pressures (Scenarios 2 - 3, 8) and Consideration of Alternative Management Strategies (Scenarios 4 - 7)}

In order to model the known mortality rates of the white-lipped peccary population in CNP in 2002 (Scenario 2), I adjusted the baseline scenario (Scenario 1) to account for mortality from poaching and simulated the population under the known hunting pressure reported by Fuller et al. [38] for males and females. All scenarios (see Table 2) use the parameters from the baseline model and the number of males and females hunted were input values under the "Harvest" section in VORTEX.

People residing near CNP hunt the peccaries opportunistically, mainly during a 4-month period (SeptemberDecember) when the herds are seen passing by the edge of the Park and near the six villages closest to CNP [30]. The extraction of gold also appears to occur in the dry season [46], and gold miners are known to hunt peccaries for subsistence while in the Park. All simulations assume that hunting occurs only during this 4-month period at the end of the wet season when the white-lipped peccary population increases its seasonal range to search for food and is more susceptible to detection by hunters [47] [48]. Because Scenario 2 incorporates mortality values from the literature (which accounts for mortality from poaching), hunting pressure is defined by these values and not by calculated levels of harvesting in VORTEX.

It has been observed that the peccaries are hunted as soon as they reach the Park borders and as they travel past villages [30]. Under current conditions, the miners poach the white-lipped peccaries that attempt to expand their range outside the Park. This makes it even difficult for tourists and Park personnel to spot the herds. Similarly, locals living around the Park do not have the same access to the peccary herds and are no longer the primary group of people hunting the animals [CNP ranger, pers. comm.]. Thus, the subsequent scenarios (Scenarios 3 - 8) assume that hunting pressure is based only on hunting by the number of illegal gold miners reported in the Park. The simulations for Scenarios 3 - 8 assume that each group of miners contains between 20 - 40 individuals [23], and that each group hunts two white-lipped peccaries per hunting month [CNP ranger, pers. comm.]. There appears to be differential exposure to hunting based on the observation that males travel in the back of the herd while females and young travel in the front of the herd and frequently escape [41]. Of the peccaries hunted, I assumed that $70 \%$ of them were males while $30 \%$ were females.

In 2006, it was reported that an estimated 30 illegal gold miners resided in CNP [46] compared to the 250 miners calculated to reside in the Park during the 2013 gold rush [24]. Table 2 summarizes the hunting scenarios based on the number of illegal miners in 2006 (Scenario 3) and 2013 (Scenario 8), as well as the peccaries hunted under alternative management scenarios where the number of miners in CNP increases in increments of 50 until reaching 2013 levels. 
Table 2. The table summarizes the scenarios simulated based on mortality rates without hunting pressure, mortality rates (with poaching) reported in Corcovado National Park in 2002, the number of miners reported during 2006 and 2013, and alternative scenarios where the number of miners increases in increments of 50 until reaching 2013 levels. Hunting is assumed to occur only by the miners during the end of the wet season when gold extracion activities occur and when the peccaries expand their foraging range (September-December). The number of males and females hunted were input values under the "Harvest" section in VORTEX.

\begin{tabular}{|c|c|c|c|c|c|c|}
\hline Scenario & Description & $\begin{array}{l}\text { Scenario } \\
\text { starting } \\
\text { year }\end{array}$ & $\begin{array}{l}\text { Miners } \\
\text { in CNP }\end{array}$ & $\begin{array}{c}\text { Total number of } \\
\text { individuals hunted } \\
\text { per end of wet season }\end{array}$ & $\begin{array}{l}\text { Males } \\
\text { hunted }\end{array}$ & $\begin{array}{c}\text { Females } \\
\text { hunted }\end{array}$ \\
\hline 1 & $\begin{array}{l}\text { Baseline scenario based on } 2002 \\
\text { mortalities for males and females in } \\
\text { CNP. No mortality from poaching. }\end{array}$ & 2002 & 0 & 0 & 0 & 0 \\
\hline 2 & $\begin{array}{l}\text { Mortality rates for males and females in } \\
\text { 2002. Includes pressure from poaching. }\end{array}$ & 2002 & 0 & 0 & 0 & 0 \\
\hline 3 & $\begin{array}{l}\text { Poaching rate based on number of } \\
\text { miners in CNP during } 2006 .\end{array}$ & 2006 & 30 & 16 & 11 & 5 \\
\hline 4 & Alternative scenario. & 2014 & 50 & 16 & 11 & 5 \\
\hline 5 & Alternative scenario. & 2014 & 100 & 32 & 22 & 10 \\
\hline 6 & Alternative scenario. & 2014 & 150 & 48 & 33 & 15 \\
\hline 7 & Alternative scenario. & 2014 & 200 & 64 & 44 & 20 \\
\hline 8 & $\begin{array}{l}\text { Poaching rate based on number } \\
\text { of miners in CNP during } 2013 .\end{array}$ & 2013 & 250 & 80 & 56 & 24 \\
\hline
\end{tabular}

\section{Results}

\subsection{Running the Simulations}

I ran 1000 simulations of the white-lipped peccary population for each of the eight scenarios. I recorded the mean final population size, the mean probability of extinction for the population after 50 years, the mean time to first extinction (if any simulations went extinct), and the mean growth rate $r$ of the population (see Table 3). The mean growth rate, $r$, is calculated prior to truncation due to the carrying capacity of the environment. Truncation refers to the addition of mortalities on the population to keep at it the upper limit, $K$.

\subsection{Growth Rates and Probabilities of Extinction}

As expected, the highest growth rate is that of the baseline scenario (Scenario $1 ; r=0.15$, SD $=0.05$ ) where hunting is not incorporated into the simulations. Even with 100 miners hunting (Scenario 5), the population shows a mean positive growth rate $(r=0.09$, $\mathrm{SD}=0.08)$. Negative growth rates are reported when there are more than 150 miners in the Park (Scenarios 6 - 8).

Under the baseline scenario, the population of white-lipped peccaries had a $0 \%$ chance of going extinct, as it did in Scenario 2 (2002 hunting level), Scenario 3 (30 miners), and Scenario 4 (50 miners). There appears to be no difference between Scenarios 3 and 4 . The probability of extinction for the population increases drastically between Scenario 5 (100 miners) and Scenario 6 (150 miners; about a 74\% increase in probability of extinction). If 250 miners continue to hunt (Scenario 8), the population will be extinct after 50 years, with the mean time to first extinction occurring in about five years.

Figure 1 plots the mean number of extant individuals for Scenarios 1 - 3 and 8 . The population trajectories for the baseline scenario and Scenarios 2 and 3 steadily increase while Scenario 8, which models the population with 250 miners in the Park during 2013, models a population that goes extinct. Figure 2 shows the mean number of extant white-lipped peccaries under various management scenarios where the number of miners in the Park increases in increments of 50 until reaching 2013 levels. The graph shows that under Scenario 7 (200 miners) and Scenario 8 (250 miners) the population goes extinct.

\subsection{Probabilities of Extinction under Various Management Scenarios}

The probabilities of extinction for various management scenarios are reported in Figure 3. Year 1 for Scenario 8 
Table 3. The table shows the mean population size of the 1000 simulated white-lipped peccary populations (which includes both extant and extinct simulations) as well as the probability of extinction of the population after 50 years. The mean time to first extinction applies only to the population simulations that went extinct in the scenario. The mean growth rate $r$ was calculated prior to truncation by the carrying capacity $K$.

\begin{tabular}{cccccc}
\hline Scenario & Miners (n) & $\begin{array}{c}\text { Mean final population } \\
\text { size (95\% C.I.) }\end{array}$ & $\begin{array}{c}\text { Mean probability of extinction (\%) } \\
\text { After } 50 \text { years }\end{array}$ & $\begin{array}{c}\text { Time to first extinction: } \\
\text { mean years (SD) }\end{array}$ & $\begin{array}{c}\text { Mean growth } \\
\text { rate } r(\mathrm{SD})\end{array}$ \\
\hline 1 & 0 & $908(898-917)$ & 0 & 0 & $0.15(0.05)$ \\
2 & 0 & $861(852-869)$ & 0 & 0 & $0.10(0.05)$ \\
3 & 30 & $901(891-910)$ & 0 & 0 & $0.13(0.05)$ \\
4 & 50 & $905(895-914)$ & 0 & 0 & $0.13(0.05)$ \\
5 & 100 & $824(807-840)$ & 7.2 & $20.7(7.6)$ & $0.09(0.08)$ \\
6 & 150 & $163(141-184)$ & 81 & $13.8(5.8)$ & $-0.07(0.29)$ \\
7 & 200 & $1(0-2)$ & 100 & $7.8(1.9)$ & $-0.37(0.44)$ \\
8 & 250 & 0 & 100 & $5.6(0.7)$ & $-0.50(0.44)$ \\
\hline
\end{tabular}



Figure 1. The figure shows the mean number of extant individuals after 1000 simulations for Scenarios 1 - 3 and Scenario 8. The starting population for each scenario was 250 white-lipped peccaries. For Scenarios 2, 3, and 8, year 0 represents the years 2002, 2006, and 2013, respectively. The figure includes standard error bars.

corresponds to the year 2013, thus year 5 is 2018 and year 10 is 2023. Scenarios 4 and 5 present promising probabilities of persistence for the peccaries where the probability of extinction for the population approaches zero when there are only 50 miners poaching and is only about 7\% after 50 years with 100 miners in the Park. This is reflected in Figure 2 where the population trajectories for both scenarios show a steady increase until they reach the carrying capacity $(K=1000, \mathrm{SD}=200)$.

The population under Scenario 6 reaches more than a 60\% chance of extinction by year 15 and the probability continues to increase as a function of time. Under Scenarios 7 and 8, the population is at more than a $95 \%$ chance of extinction by year 10 .

\section{Discussion}

\subsection{Growth Rates and Probabilities of Extinction}

Growth rates are valuable indicators of the viability of a population. Bodmer et al. [15] examined the likelihood 


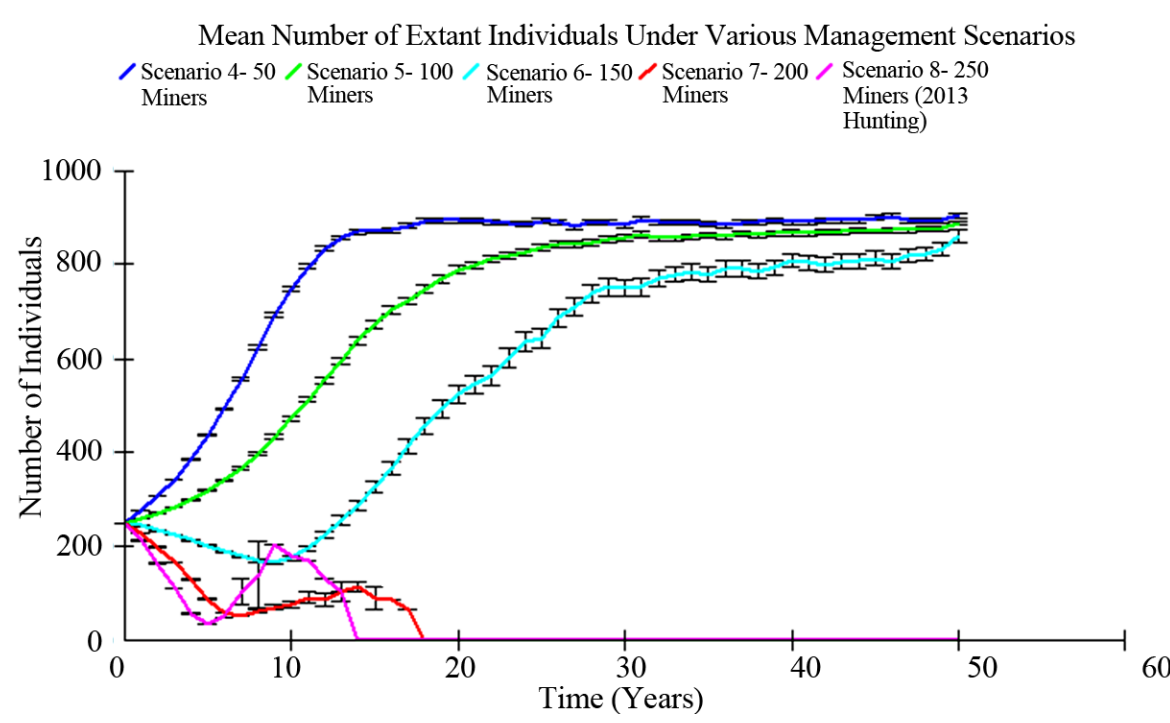

Figure 2. The figure shows the mean number of extant individuals after 1000 simulations for Scenarios 4 - 8. The starting population for each scenario was 250 white-lipped peccaries. For Scenario 8, year 0 represents year 2013. For all other scenarios in the figure, year 0 represents year 2014. The figure includes standard error bars.

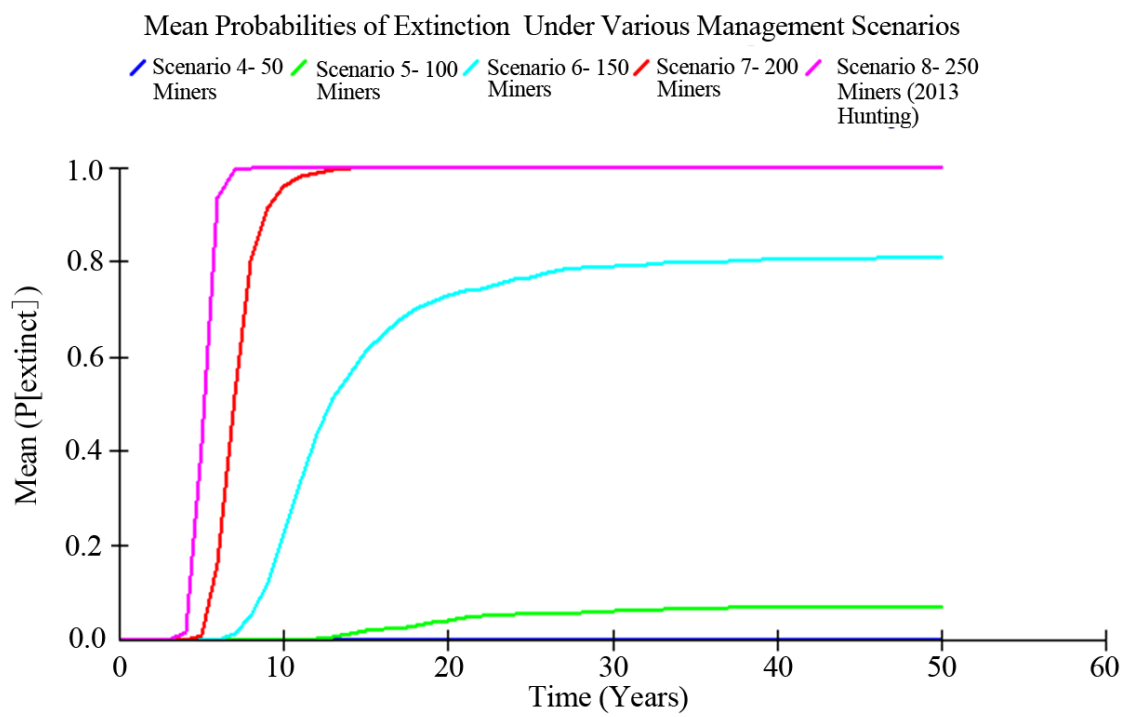

Figure 3. The figure shows the probabilities of extinction under the 2013 scenario where 250 miners were reported in Corcovado National Park (Scenario 8) as well as various management scenarios where the number of miners varies by increments of 50 people. For Scenario 8, year 0 represents year 2013. For all other scenarios in the figure, year 0 represents 2014. Note the change in probabilities of extinction between Scenario 5 and Scenario 6 after 50 miners have been added.

of extinction in Amazonian mammals and calculated estimates of the species' intrinsic rate of natural increase, $r_{\max }$. For the white-lipped peccary population in the Northeastern Peruvian Amazon, the authors reported a $r_{\max }$ of 0.84. In my PVA, the highest mean growth rate for the population in CNP resulted from the baseline scenario where no poaching was accounted for in the mortality rates of males and females $(r=0.15$, SD $=0.5)$. This suggests that mortality rates of the white-lipped peccary population in 2002 were very high in CNP compared to those in the Peruvian Amazon in 1997. It is important to note that some of the cause-specific mortality rates reported by Fuller et al. [38] have wide confidence intervals (i.e. mortality rate for females from unknown causes, but not poaching $=0.12,95 \%$ C.I. $=0.04-0.20$ ), which may be a possible explanation for the difference in $r$ 
reported by Bodmer et al. [15] and the one calculated in my baseline scenario.

My simulations confirm Fuller et al.'s [38] contention that the population in 2002 may have been maintaining itself. In 2006, it was reported that about 30 people were mining in the Park. There appears to be no difference in the mean final population sizes for the scenarios with 30 miners and 50 miners because I assumed that the number of male and female peccaries hunted for sustenance was about the same in both cases. Nevertheless, had the reported hunting levels from 2002 which use mortality rates that include poaching mortality from Fuller et al. [38] and those from 2006 (30 miners) had been maintained (or had they increased to 50 miners poaching), the population of white-lipped peccaries would have virtually no chance of going extinct even after 50 years.

The white-lipped peccary population shows positive values for $r$ even with 100 miners in the Park, though the scenario does report iterations that go extinct. For the iterations that go extinct, the mean time to first extinction is about 20.7 years $(\mathrm{SD}=7.6$ ). For this scenario the population has a mean probability of extinction of about $7.2 \%$ after 50 years. It appears that the white-lipped peccary population may be viable even with up to 100 miners in CNP.

Under the 2013 hunting pressure (Scenario 8), there is a 99\% of extinction within ten years, with the mean time to first extinction occurring in about six years (by 2019) if the number of miners is not controlled immediately. The threshold that turns $r$ into a negative value appears to occur when 150 or more miners are poaching. This is reflected in the calculations of probabilities of extinction (Figure 3) where the population reaches about a 23\% probability of extinction at year 10 and about a 61\% probability of extinction at year 15 with 150 miners. These results indicate that it would require Park enforcement to reduce the number of miners to 100 to maintain a viable population that has very low probabilities of going extinct. A reduction of miners from 250 to 150 would not suffice since the mean time to first extinction is about 14 years (year 2028) under the scenario with 150 miners.

Fragoso [49] attributed the local disappearance of a white-lipped peccary population in Maraca Island Ecological Reserve, Brazil, to mortality from overhunting and eventual reproductive failure. My model assumes that more males than females are harvested per end of wet season. The selective harvesting of males and females in the population of each scenario may be a possible explanation for the high increase in probability of extinction that occurs when the number of miners increases from 100 to 150 . Studies on the effects of selective harvesting of male and female ungulates have reported a wide range of mechanisms by which populations may be negatively affected [50]. Adult males are more susceptible to hunting than females because of their behavior of traveling in the back of the herd [41] and because hunters tend to show preference towards adults with a large body size [50]. Selective harvesting of males tends to shift the population sex ratio towards females and may reduce the mean age of males in the population, which may in turn reduce recruitment and result in low population growth rates [50]. Furthermore, male-biased harvests can reduce female fecundity (number of young born) and lead to population declines [51].

Another possible explanation for the extinction threshold may be the harvesting intensity on female whitelipped peccaries. Because a polygynous system prevails, and because more males will continue to mate with females regardless of the female population size, the reduction in number of females may be the limiting factor in the growth of the population [50]. In my model, the threshold occurs when the number of females hunted increases from 10 (100 miners) to 15 (150 miners). During the same poaching conditions, the number of males hunted increases from 32 (100 miners) to 48 (150 miners). This is alarming, as the threshold requires only about five more females and 16 more males to be poached during the 4-month period in order to increase the probability of extinction of the population by about 74\% from one scenario to the next. It appears that low-density ungulate populations with low reproductive rates may show high adult mortality because of a greater number of older individuals [52]. This may be a possible case in the model, where not enough young, reproducing females are present in the population at one time due to strong hunting pressure. Furthermore, elasticity analyses have showed that the population growth rate of female ungulates may be heavily impacted when the mortalities of sexually reproducing females are increased [53] [54].

\subsection{Improvement of the Model}

Due to the lack of current demographic information on the white-lipped peccary population in CNP and the assumptions that were made, it is important to highlight the improvements that can be made to the model. The VORTEX simulations would benefit from more current mortality rates as well as current estimates of causespecific mortality rates, notably poaching. The male and female mortality rates for the population in CNP are 
from 12 years ago and were calculated based on the monitoring of 25 females and 11 males [38]. Although Fuller et al.'s [38] study took place over six years, a more thorough study would track a greater number of male and female peccaries to reduce the sizes of the confidence intervals for cause-specific mortality rates. As noted above, there is a threshold between 100 and 150 poachers mining. No variation in survival across ages is assumed [42] because studies on the survival rates of white-lipped peccaries are lacking. More thorough and recent records of mortality rates that account for variation in survival across ages may shift the threshold as well as the probabilities of extinction for the various scenarios. There may be variation in survival across age classes given that it is more likely for miners to hunt adult peccaries rather than juveniles if they are being poached to feed a large group of people.

\subsection{Management Recommendations}

From 1990-1994, it was found that the level of law enforcement in CNP was directly linked to the abundance of animals in the Park [55]. The species more negatively affected by the lack of law enforcement were those that were poached for consumption, such as the white-lipped peccary. CNP had a stricter law enforcement program compared to that of the nearby Golfo Dulce Forest Reserve, which accounted for a greater abundance of animals in Corcovado than in the Forest Reserve. I suggest that the CNP administration invest in stricter law enforcement programs, in contracting scientists and staffs to gather accurate estimates of current mortality rates for male and female white-lipped peccaries, and in obtaining accurate estimates of monthly hunting rates. Because my simulations suggest that the population may go extinct in less than ten years under the 2013 hunting scenario and because management resources may be limited, these resources should first be invested in removing around 150 miners. Full removal of the miners would be ideal, but a viable population may be maintained if 100 miners are left in CNP.

Enforcing anti-mining and anti-poaching laws that protect the white-lipped peccary population would prevent a negative cascade of events for CNP. It is possible that reducing white-lipped peccary numbers could lead to an ecological extinction, reducing its function as an ecosystem-architect, seed predator, seed disperser [5] [55], and major prey for the endangered jaguar population [28] [34]. A further reduction in white-lipped peccary abundance may induce the switching of jaguars from one prey species to another [56] [57], which could have unprecedented ecological ramifications. Because miners also hunt other species for sustenance while in the Park, law enforcement may help reduce possible risks of population declines for species that may be susceptible to declines due to poaching and for which there is a lack of biological information. Furthermore, stricter law enforcement will impede further transformation of the landscape and mercury contamination of the water that results from mining operations. A local extinction may be prevented through habitat protection and improved management of hunting [58]. In this case, complete prohibition of hunting may be required especially due to the assumptions and uncertainties surrounding the modeling of the population trajectories.

\section{Conclusion}

It is likely that the population of white-lipped peccaries in Corcovado National Park will go extinct in the near future if immediate management efforts are not implemented. CNP has been known to be one of the most well protected areas under Costa Rica's National Park System [55]. In order to maintain this reputation, there is an urgent need for stricter law enforcement to reduce the number of miners poaching inside the Park. Strong law enforcement programs that limit the unsustainable harvest of endangered species will ensure that CNP remains the largest stronghold for the white-lipped peccary in Costa Rica.

\section{Acknowledgements}

C. J. R. thanks E. Carrillo, J. C. Sáenz, and R. Salom-Pérez, and the staff at the Corcovado National Park Administrative Headquarters for providing information, data, and reports on the white-lipped peccary population and for helping to define the scope of this study, as well as two anonymous Park rangers at La Leona Ranger Station in Corcovado National Park. The author also gratefully acknowledges D. S. Wilcove and M. W. Tingley for their guidance and insightful advice throughout the course of the study. This study was made possible by the financial support and generosity of the Program in Latin American Studies and the Department of Ecology and Evolutionary Biology at Princeton University. 


\section{References}

[1] Vaughan, C. and Rodriguez, C. (1997) Managing beyond Borders: The Costa Rican National System of Conservation Areas (SINAC). In: Meffe, G.K. and Carroll, C.R., Eds., Principles of Conservation Biology, Sinauer Associates, Sunderland, 441-451.

[2] Myers, N., Mittermeier, R., Mittermeier, C., Fonseca, G.D. and Kent, J. (2000) Biodiversity Hotspots for Conservation Priorities. Nature, 403, 853-858. http://dx.doi.org/10.1038/35002501

[3] Vaughan, C.A. (1981) Parque Nacional Corcovado. Plan de Manejo y Desarrollo, EUNA, Heredia.

[4] Phillips, P.R. (1993) Key to Vegetation Types for the Osa Peninsula, Costa Rica. Center for Space Research, University of Texas, Austin.

[5] Altrichter, M., Taber, A., Beck, H., Reyna-Hurtado, R., Lizarraga, L., Keuroghlian, A., et al. (2011) Range-Wide Declines of a Key Neotropical Ecosystem Architect, the Near Threatened White-Lipped Peccary Tayassu pecari. Oryx, 46, 87-98. http://dx.doi.org/10.1017/S0030605311000421

[6] Keuroghlian, A., Desbiez, A., Reyna-Hurtado, R., Altrichter, M., Beck, H., Taber, A. and Fragoso, J.M.V. (2013) Tayassu pecari. IUCN 2013, IUCN Red List of Threatened Species, Version 2013.2. www.iucnredlist.org

[7] Kiltie, R.A. (1981) Distribution of Palm Fruits on a Rain Forest Floor: Why White-Lipped Peccaries Forage Near Objects. Biotropica, 13, 141-145. http://dx.doi.org/10.2307/2387716

[8] Beck, H., Thebpanya, P. and Filiaggi, M. (2010) Do Neotropical Peccary Species (Tayassuidae) Function as Ecosystem Engineers for Anurans? Journal of Tropical Ecology, 26, 407-414. http://dx.doi.org/10.1017/S0266467410000106

[9] Hubbel, S.P. (1979) Tree Dispersion, Abundance and Diversity in a Tropical Dry Forest. Science, 203, 1299-1309. http://dx.doi.org/10.1126/science.203.4387.1299

[10] Howe, H.F. (1989) Scatter- and Clump-Dispersal and Seedling Demography: Hypothesis and Implications. Oecologia, 79, 417-426. http://dx.doi.org/10.1007/BF00384323

[11] Beck, H. and Terborgh, J. (2002) Groves versus Isolates: How Spatial Aggregation of Astrocaryum murumuru Palms Affect Seed Removal. Journal of Tropical Ecology, 18, 275-288. http://dx.doi.org/10.1017/S0266467402002183

[12] Beck, H. (2006) A Review of Peccary-Palm Interactions and Their Ecological Ramifications across the Neotropics. Journal of Mammalogy, 87, 519-530. http://dx.doi.org/10.1644/05-MAMM-A-174R1.1

[13] Keuroghlian, A. and Eaton, D.P. (2008) Fruit Availability and Peccary Frugivory in an Isolated Atlantic Forest Fragment: Effects on Peccary Ranging Behavior and Habitat Use. Biotropica, 40, 62-70.

[14] Leopold, A.S. (1959) Fauna Silvestre de México. Instituto Mexicano de Recursos Naturales Renovables, México D.F.

[15] Bodmer, R.E., Eisenberg, J.F. and Reford, K.H. (1997) Hunting and the Likelihood of Extinction of Amazonian Mammals. Conservation Biology, 11, 460-466. http://dx.doi.org/10.1046/j.1523-1739.1997.96022.x

[16] Gottdenker, N. and Bodmer, R.E. (1998) Reproduction and Productivity of White-Lipped and Collared Peccaries in the Peruvian Amazon. Journal of Zoology, 245, 423-430. http://dx.doi.org/10.1111/j.1469-7998.1998.tb00116.x

[17] Sowls, L.K. (1997) Javelinas and Other Peccaries: Their Biology, Management, and Use. Texas A\&M University Press, College Station.

[18] Fragoso, J.M.V. (1998) Home Range and Movement Patterns of White-Lipped Peccaries (Tayassu pecari) Herds in the Northern Brazilian Amazon. Biotropica, 30, 458-469. http://dx.doi.org/10.1111/j.1744-7429.1998.tb00080.x

[19] Fragoso, J.M.V. (1994) Large Mammals and the Community Dynamics of an Amazonian Rain Forest. Ph.D. Thesis, University of Florida, Gainesville.

[20] Peres, C.A. (1996) Population Status of White-Lipped Tayassu pecari and Collared Peccaries T. tajacu in Hunted and Unhunted Amazonian Forests. Biological Conservation, 77, 115-123. http://dx.doi.org/10.1016/0006-3207(96)00010-9

[21] Cullen, Jr., L., Bodmer, R.E. and Pádua, C.V. (2000) Effects of Hunting in Habitat Fragments of the Atlantic Forests, Brazil. Biological Conservation, 95, 49-56. http://dx.doi.org/10.1016/S0006-3207(00)00011-2

[22] Carbajal, G.C. and Martinez, E.V. (2013) Seccion de Operaciones, I y II Periodo Operacional. Operativo Emergente Problematica Peninsula de Osa.

[23] Minería de Oro (2013) INOGO: Iniciativa Osa Y Golfito, 1-9. http://www.minae.go.cr

[24] Diaz, L. (2013) 250 invasores destrozan Corcovado para buscar oro. La Nacion. http://www.nacion.com/nacional/invasores-destrozan-Corcovado-buscar-oro_0_1353664645.html

[25] Diaz, L. (2013) Ni más armas ni más vigilancia salvarán a Corcovado de oreros, dice René Castro. La Nacion. http://www.nacion.com/nacional/Rene-Castro-ministro-Ambiente-Corcovado 0 1354864535.html

[26] Diaz, L. (2013) Falta de empleo empuja a muchos a la extracción de oro. La Nacion. http://www.nacion.com/nacional/Falta-empleo-empuja-extraccion-oro_0_1354064603.html 
[27] Garcia, D. (2013) Población de jaguares se vería en peligro por caza local de chanchos de monte en Corcovado. http://www.crhoy.com/poblacion-de-jaguares-se-veria-en-peligro-por-caza-local-de-chanchos-de-monte-en-corcovado/

[28] Carrillo, E. and Sáenz, J. (2011) 20 años de monitoreo de cinco especies indicadoras de la salud del Bosque en el Parque Nacional Corcovado, Costa Rica. Universidad Nacional, Heredia. http://www.observatorioambiental.una.ac.cr/index.php?option=com booklibrary\&task=view\&id=10\&catid=44\&Itemi $\underline{\mathrm{d}=37}$

[29] Madrigal, M. (2013) Informe Tecnico Para La Inhabilitacion de Tuneles en el Parque Nacional Corcovado. Sistema Nacional de Areas Protegidas: Direccion de Areas Protegidas. http://www.minae.go.cr

[30] Altrichter, M. and Almeida, R. (2002) Exploitation of White-Lipped Peccaries Tayassu pecari (Artiodactyla: Tayassuidae) on the Osa Peninsula, Costa Rica. Oryx, 36, 126-132.

[31] Borge, C. and Herrera, B. (2006) Análisis de amenazas y oportunidades para la conservación en ACOSA. Informe Técnico No. 3. San Jose, Costa Rica, 95.

[32] Altrichter-Cateula, M. and Almeida, R. (2009) Los chanchos de monte Tayassu pecari tienen guardas personales en la Península de Osa, Costa Rica. Suiform Soundings, 9, 18-20. https://sites.google.com/site/wildpigspecialistgroup/iucnssc-wild-pig-specialist-group/suiform-soundings-2

[33] Sáenz J. and Carrillo E. (2002) Chancho de monte en Península de Osa, su ecología y su importancia. Ambientales (Costa Rica), 2002, 4-12.

[34] Salom-Pérez, R., Carillo, E., Sáenz, J.C. and Mora, J.M. (2007) Critical Conditions of the Jaguar Panthera onca Popu lation in Corcovado National Park, Costa Rica. Oryx, 41, 51-56. http://dx.doi.org/10.1017/S0030605307001615

[35] Akçakaya, H.R. and Sjögren-Gulve, P. (2000) Population Viability Analysis in Conservation Planning: An Overview. Ecological Bulletins, 48, 9-21. http://life.bio.sunysb.edu/ee/akcakayalab/PVA1.pdf

[36] Miller, P.S. and Lacy, R.C. (2005) VORTEX: A Stochastic Simulation of the Extinction Process. Version 9.50. User's Manual. Conservation Breeding Specialist Group (SSC/IUCN), Apple Valley, Minnesota.

[37] Lacy, R.C. and Pollak, J.P. (2014) Vortex: A Stochastic Simulation of the Extinction Process. Version 10.0, Chicago Zoological Society, Brookfield.

[38] Fuller, T.K., Carillo, E. and Sáenz, J.C. (2002) Survival of Protected White-Lipped Peccaries in Costa Rica. Canadian Journal of Zoology, 80, 586-589. http://dx.doi.org/10.1139/z02-020

[39] Villalobos Céspedes, J. (2001) Dinámica del tamaño y composición de las manadas de chanchos de monte (Tayassu pecari) en el Parque Nacional Corcovado, Costa Rica. Master’s Thesis, Universidad Nacional, Heredia.

[40] Bustamante, A., Moreno, R. and Artavia, A. (2013) Saínos y Chanchos de monte (Artiodactyla: Tayassuidae): Situación actual y conservación en Osa, Costa Rica. Suiform Soundings, 12, 30-31. https://sites.google.com/site/wildpigspecialistgroup/iucnssc-wild-pig-specialist-group/suiform-soundings-2

[41] Altrichter, M.A., Carillo, E., Sáenz, J. and Fuller, T.K. (2001) White-Lipped Peccary (Tayassu pecari, Artiodactyla: Tayassuidae) Diet and Fruit Availability in a Costa Rican Rain Forest. Revista de Biologia Tropical, 49. http://www.scielo.sa.cr/scielo.php?pid=S0034-77442001000300038\&script=sci_arttext

[42] Bodmer, R.E. (1989) Ungulate Biomass in Relation to Feeding Strategy within Amazonian Forests. Oecologia, 81, 547-550. http://dx.doi.org/10.1007/BF00378967

[43] Toigo, C., Servanty, S., Gaillard J.M., Brandt, S. and Baubet, E. (2008) Disentangling Natural from Hunting Mortality in an Intensively Hunted Wild Boar Population. Journal of Wildlife Management, 72, 1532-1539.

[44] Robinson, J.G. and Redford, K.H. (1986) Intrinsic Rate of Natural Increase in Neotropical Forest Mammals: Relationship to Phylogeny and Diet. Oecologia, 68, 516-520. http://dx.doi.org/10.1007/BF00378765

[45] Ralls, K., Ballou, J.D. and Templeton, A.R. (1988) Estimates of Lethal Equivalents and the Cost of Inbreeding in Mammals. Conservation Biology, 2, 185-93. http://dx.doi.org/10.1111/j.1523-1739.1988.tb00169.x

[46] Sierra, C., Castillo, E. and Arguedas, S. (2006) Diagnósticos biofísico, social, económico, productivo y análisis institucional. Documento de Trabajo Para el Plan de Manejo del Parque Nacional Corcovado.

[47] Altrichter, M. (1997). Estrategia de alimentación y comportamiento del chancho cariblanco Tayassu pecari en unbosque húmedo tropical de Costa Rica. M. Sc. Thesis, National University of Costa Rica, Heredia.

[48] Carillo, E., Sáenz, J.C. and Fuller, T.K. (2002) Movements and Activities of White-Lipped Peccaries in Corcovado National Park, Costa Rica. Biological Conservation, 108, 317-324. http://dx.doi.org/10.1016/S0006-3207(02)00118-0

[49] Fragoso, J.M.V. (2004) A Long-Term Study of White-Lipped Peccary (Tayassu pecari) Population Fluctuation in Northern Amazonia. In: Silvius, K., Bodmer, R.E. and Fragoso, J.M.V., Eds., People in Nature, Wildlife Conservation in South and Central America. Columbia University Press, New York, 286-296.

[50] Milner, J.M., Nilsen, E.B. and Andreassen, H.P. (2007) Demographic Side Effects of Selective Hunting in Ungulates 
and Carnivores. Conservation Biology, 21, 36-47. http://dx.doi.org/10.1111/j.1523-1739.2006.00591.x

[51] Ginsberg, J. and Milner-Gulland, E.J. (1994) Sex-Biased Harvesting and Population Dynamics in Ungulates: Implications for Conservation and Sustainable Use. Conservation Biology, 8, 157-166. http://dx.doi.org/10.1046/j.1523-1739.1994.08010157.x

[52] Festa-Bianchet, M., Gaillard, J.M. and Côté, S.D. (2003) Variable Age Structure and Apparent Density Dependence in Survival of Adult Ungulates. Journal of Animal Ecology, 72, 640-649. http://dx.doi.org/10.1046/j.1365-2656.2003.00735.x

[53] Schaefer, J.A., Veitch, A.M., Harrington, F.H., Brown, W.K., Theberge, J.B. and Luttich, S.N. (1999) Demography of Decline of the Red Wine Mountains Caribou Herd. Journal of Wildlife Management, 63, 580-587. http://dx.doi.org/10.2307/3802646

[54] Gaillard, J.M., Festa-Bianchet, M., Delorme, D. and Jorgenson, J. (2000) Body Mass and Individual Fitness in Female Ungulates: Bigger Is Not Always Better. Proceedings of the Royal Society of London B, 267, 471-477. http://dx.doi.org/10.1098/rspb.2000.1024

[55] Carrillo, E., Wong, G. and Cuarón, A.D. (2000) Monitoring Mammal Populations in Costa Rican Protected Areas under Different Hunting Restrictions. Conservation Biology, 14, 1580-1591. http://dx.doi.org/10.1046/j.1523-1739.2000.99103.x

[56] Carillo, E. (2000) Ecology and Conservation of White-Lipped Peccaries and Jaguars in Corcovado National Park. Ph.D. Thesis, University of Massachusetts, Amherst.

[57] Cavalcanti, S.M.C. and Gese, E.M. (2010) Kill Rates and Predation Patterns of Jaguars (Panthera onca) Preying on Livestock and Native Prey in the Southern Pantanal, Brazil. Journal of Mammalogy, 91, 722-736. http://dx.doi.org/10.1644/09-MAMM-A-171.1

[58] Galetti, M., Giancomini, H.C., Buenos, R.S., Bernardo, C.S.S., Marques, R.M., Bovendrop, R.S., et al. (2009) Priority Areas for the Conservation of Atlantic Forest Large Mammals. Biological Conservation, 142, 1229-1241. http://dx.doi.org/10.1016/j.biocon.2009.01.023 
Scientific Research Publishing (SCIRP) is one of the largest Open Access journal publishers. It is currently publishing more than 200 open access, online, peer-reviewed journals covering a wide range of academic disciplines. SCIRP serves the worldwide academic communities and contributes to the progress and application of science with its publication.

Other selected journals from SCIRP are listed as below. Submit your manuscript to us via either submit@scirp.org or Online Submission Portal.
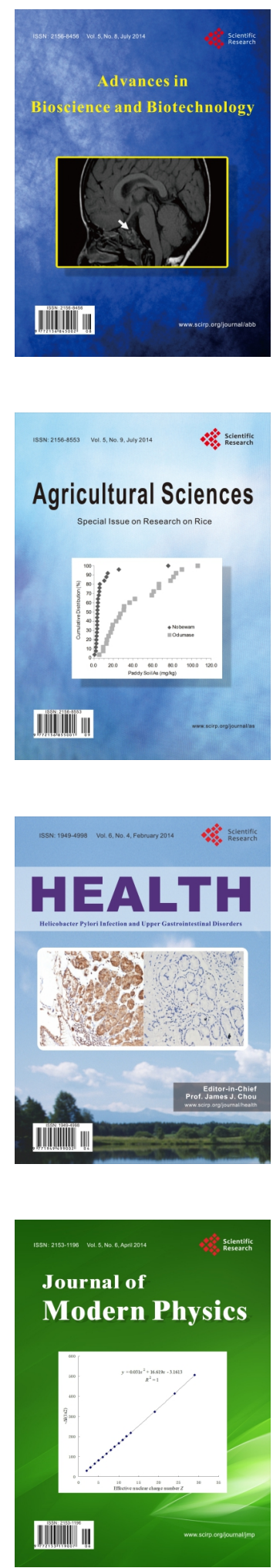
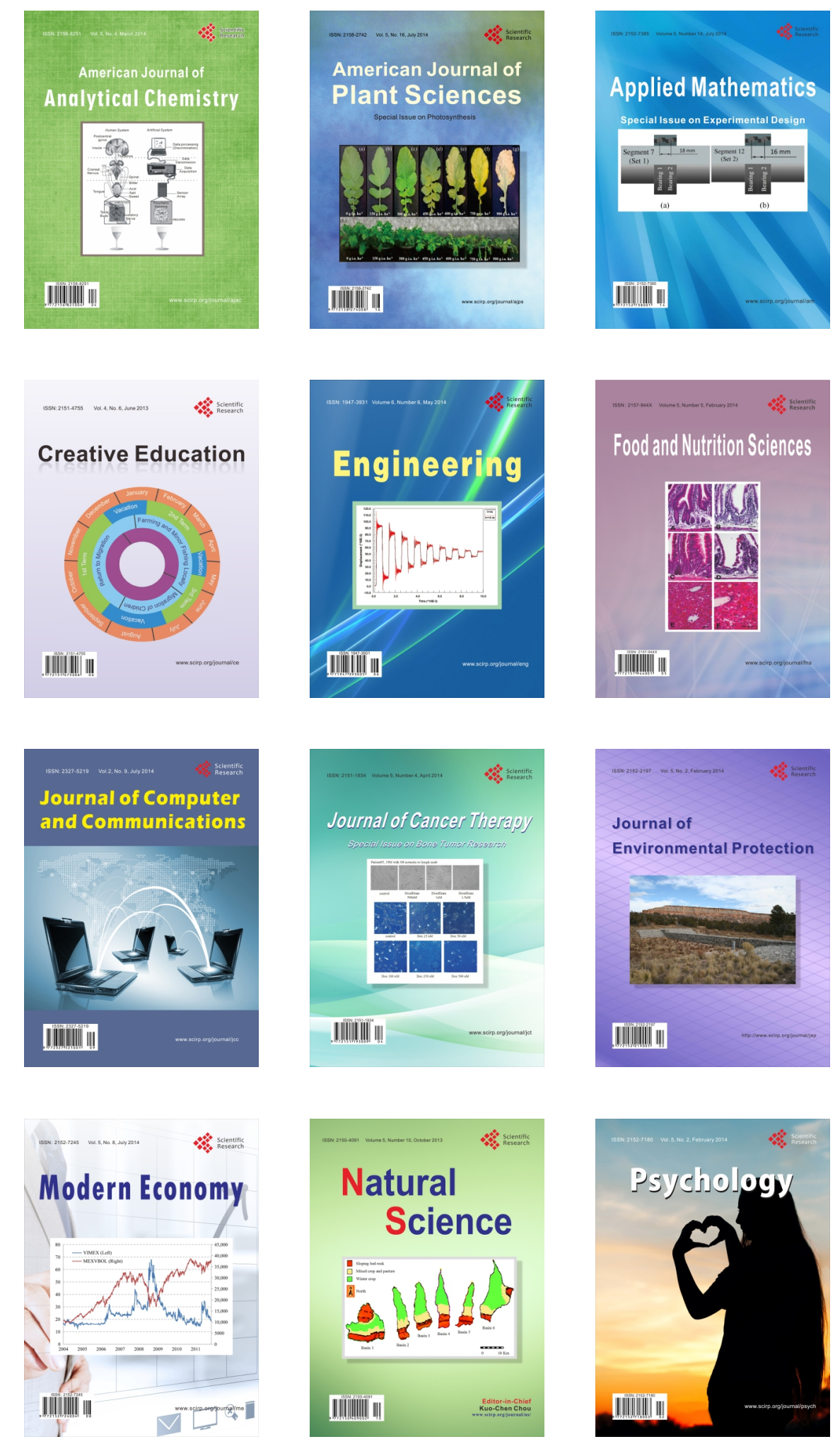